\title{
Case study of the physics component of an integrated curriculum
}

\author{
R. Beichner, L. Bernold, E. Burniston, P. Dail, R. Felder, J. Gastineau, M. Gjertsen, \\ and J. Risley \\ North Carolina State University, Raleigh, North Carolina 27695
}

(Received 14 November 1997; accepted 12 April 1999)

\begin{abstract}
Over a four-year time span, several departments at North Carolina State University offered experimental sections of courses taken by freshman engineering students. The acronym IMPEC (Integrated Math, Physics, Engineering, and Chemistry curriculum) describes which classes were involved. This paper discusses the physics component of the curriculum and describes the impact of the highly collaborative, technology-rich, activity-based learning environment on a variety of conceptual and problem-solving assessments and attitude measures. Qualitative and quantitative research results indicate that students in the experimental courses outperformed their cohorts in demographically matched traditional classes, often by a wide margin. Student satisfaction and confidence rates were remarkably high. We also noted substantial increases in retention and success rates for groups underrepresented in science, math, and engineering. Placing students in the same teams across multiple courses appears to have been the most beneficial aspect of the learning environment. (C) 1999 American Association of Physics Teachers.
\end{abstract}

\section{INTRODUCTION}

The first year of the engineering curriculum can be quite difficult and takes its toll on students. Many studies ${ }^{1,2}$ have attempted to understand the cause of this substantial "narrowing of the pipeline" leading to employment as a scientist or engineer. This project was an attempt to promote student success by combining the most effective features of a wide variety of new and old methodologies for teaching technical information. Over a four-year time span, faculty from four disciplines combined their efforts to see if they could minimize attrition and improve student understanding and attitudes toward the topics covered during a typical freshman year at a large engineering school. Subjects studied during this critical time in the pre-engineer's preparation include differential and integral calculus, general chemistry, the first semester of physics (statics, kinematics and dynamics), and a general introduction to the field of engineering. This paper deals with the revisions made directly to the physics component as well as aspects of the rest of the experimental curriculum that may have indirectly affected student success in physics. The focus is on the 1995-96 and 1996-97 academic years.

Because of demonstrated weaknesses ${ }^{3-5}$ in the understanding of introductory physics students following traditional instruction, this aspect of the curriculum looked like it would be a promising area for improvement. The freedom provided by the experimental nature of the project allowed us to combine many different research-based approaches to teaching and learning, including activity-based pedagogies, ${ }^{6-9} \mathrm{col}-$ laborative learning, ${ }^{10,11}$ the integration of curricula, ${ }^{12}$ context-rich problems, ${ }^{13,14}$ and the use of technology. ${ }^{15-17}$ We were looking to see if the proper combination of elements from these successful approaches would allow us to improve learning and attitudes. By paying close attention to inter-student and student-instructor interactions in controlled surroundings and situations, we also hoped to determine what aspects of classroom layout and usage facilitated the type of student-centered learning environment championed by these pedagogies.

\section{INSTRUCTIONAL ENVIRONMENT}

During the fall semester, students took calculus, general chemistry, and a one-credit introduction to engineering. In the spring, the students took the second semester of calculus, the first semester of physics, and a second one-credit engineering course. Besides these 10 credit hours each semester, students also registered for 4-8 hours of other classes like English in the fall and a programming course in the spring.

The experimental classes were all taught in a single room. Students were assigned to three-person teams where they worked on homework and lab assignments. Membership was designed so that the groups were heterogeneous by ability as measured by GPA and academic background. Women and minorities were paired within groups to the greatest possible extent. These same teams extended across all three integrated courses. Roles of recorder, checker, and coordinator were rotated with each assignment so that all aspects of teamsmanship could be practiced by each group member. Students received explicit instruction on how to work in groups and were given protocols for dealing with problems that might arise when different people work together on common tasks. Grading schemes were devised to ensure both individual accountability and positive interdependence. Descriptions of the internal workings of the groups were part of many assignments, ensuring a processing of group operation, which is recognized ${ }^{10,11}$ as important to ensuring group success. A variety of seating arrangements ranging from long benches to round tables of differing diameters were tested to see which would best facilitate group work. The room was open 24 hours/day (although it was used by several other classes) and was often the site of outside-of-class group meetings set up by the students.

A great deal of effort was given to developing activities that would keep students' interest and minimize the need for lecturing. The limitations of the "transmissionist" style of instruction have been clearly documented in numerous studies, and have perhaps been most clearly stated by Arnold Arons: ${ }^{18}$

"...I point to the following unwelcome truth: much as we might dislike the implications, research is showing 
that didactic exposition of abstract ideas and lines of reasoning (however engaging and lucid we might try to make them) to passive listeners yields pathetically thin results in learning and understanding-except in the very small percentage of students who are specially gifted in the field.' (p. vii)

Of course, that small number of students who are particularly successful in traditional instructional settings often go on to academia where they teach the way they were taught, perpetuating an often inappropriate instructional methodology.

Although there was some lecturing to prepare the way for the study of new topics, provide an organizational scheme, or motivate the students, much of the class time was spent working on special activities. During these tasks, students had to make predictions, develop models of physical phenomena, collect and analyze data from probes, and work on design projects. Students were responsible for reading material from the textbook and asking about difficulties when they arose. It was explained to them that the only occasions when content from the book would be directly addressed was when their questions about it were being discussed or at those times when the instructor had an alternative way of presenting a topic. (This permitted coverage of the same material as the traditional course, while spending more class time on specific problem areas.) Quizzes on the text, coupled with weekly homework assignments of end-of-chapter problems, ensured that most students were taking their reading responsibility seriously. Except for chemistry, there were no separately scheduled labs. Laboratory hours were combined with the time normally reserved for large-scale lecturing, resulting in 5 hours/week of chemistry (fall) or physics (spring), 5 hours/week of math, and 2 hours/week of engineering.

Although there was a default schedule describing which courses were to be taught during specific time periods, there were some situations (exams, field trips, etc.) where the instructors modified the schedule to better fit the students' needs. There were also several occasions where more than one of the instructors would be in the classroom at the same time. Students seemed to particularly enjoy special workshops on topics like differential equations, "jigsaw" projects (where individual group members collected information on different topics and then shared their expertise with the rest of their team), and chances to work on semester-long, complex design projects. They also appeared to value explicit skill development and metacognitive training, including discussions of the outcome of a personal learning styles inventory. ${ }^{19}$ The engineering course included sessions on how to work in teams, effective ways to communicate in writing and orally, and time management.

Technology was used to create an environment that focused student attention on the topic of discussion. We varied the number of students per computer to study the implications for group dynamics. The computers were available to the students at all times. Field notes of the classes reveal that the phrase "Monitors off!' was heard occasionally as the instructor brought students back on task and away from web surfing or e-mailing. In spite of this potential for distraction, continuous accessibility to computers with MBL interfaces and software (for curve fitting, conducting video analyses, etc.) added enormously to the classroom milieu.

A wide variety of hands-on physics activities were developed for the students or adapted from existing curricula like
Workshop Physics, ${ }^{20}$ Physics by Inquiry, ${ }^{6}$ Concept Tests, ${ }^{21}$ and ALPS worksheets. ${ }^{22}$ Students were regularly directed to model physical phenomena with Interactive Physics (a simulation engine) and to compare their results with data collected from equivalent real-world situations. Studentgenerated models were then modified to account for discrepancies between theory and experiment. Using technology to present real and simulated situations for study freed the instructors to move about the classroom and enter into Socratic dialogs ${ }^{23}$ with the students. Because of fast connections to the Internet, the students were able to search Web pages from around the world for facts relevant to the task at hand. They were then able to use local productivity tools like spreadsheets and symbolic algebra processors to work with the information they were accumulating. Ready access to these tools made use of them an everyday occurrence, no different than using a calculator. This not only was apparent in the students' proficiency, but also in the ease with which instructors would change the flow of their lessons to utilize technology to address a student question.

In most cases, labs were conducted as short exercises directly and immediately related to the material being discussed. For example, during an introduction to the concept of center of mass, a female student challenged the instructor with the questions: "Why are we learning this? What is it good for?', (We found that the students, especially when supported by their peers, quite commonly expressed this type of concern. We believe this behavior indicates that they were thinking critically about the material.) These questions provided a natural opportunity for the instructor to begin a "mini-lab" utilizing the Interactive Physics simulation engine. (The students probably assumed that the activity was an impromptu one, and no effort was made to dispel that notion.) The simulation began with the instructor building a simple situation where one ball was thrown into another ball that was freely falling. On their own the students related this to an earlier "Monkey and Hunter'" demonstration so it was clear that they understood the physical situation being represented. The program was then adjusted to show the system's center of mass moving in a smooth parabolic arc across the screen. The instructor then showed that if gravity were not acting, the center of mass would move at constant velocity, thereby illustrating the application of Newton's first law to the system. The instructor then added another ball with a different initial velocity so that the three objects collided in a complicated manner. Students were asked to predict the path of the system's center of mass. Some guessed correctly, but most did not. After running the simulation, the students appeared to grasp the idea that the c.m. still moved uniformly.

At this point the instructor directed the students to build their own simulations. After they had modeled several simple arrangements of two or three objects, they were told to come up with a situation where the c.m. did not move in a predictable manner. They tried a wide variety of arrangements, including irregularly shaped objects held together by springs and strings that were sent spinning in erratic paths after a dozen or more collisions with other objects. In every case, the students discovered that the system c.m. moved in a parabolic arc (or with constant velocity if gravity was "'turned off', ) as if a single object were experiencing projectile motion. The questions that started the whole endeavor were then repeated and the students were easily able to answer them for themselves. The entire activity took less than $10 \mathrm{~min}$. 
In another exercise, students spent a considerable amount of time with hands-on activities and had to submit a written lab report, exercising important communications skills in addition to building a better understanding of physical concepts. In this case, each group of students was given a large spring and a $100 \mathrm{~g}$ mass. They were asked to predict the motion of the mass as it oscillated at the end of the spring, but were not told how to make those predictions. All groups realized they needed an estimate of the spring constant. Some determined its value by measuring the displacement caused by the hanging mass. Others simply used a force meter (which was merely a previously calibrated spring) to find $k$. The students then quickly sketched graphs of position versus time and indicated the expected oscillation period, after which each group set about oscillating their mass/spring system and recording the time. Photographic records of the activity show at least four different ways in which groups conducted this portion of the lab. In each case, the measured period differed substantially from the predicted value. This disparity was not a major concern to the students until they began to realize that repeating their measurements resulted in the same unexpected value. Anxiety increased once comparisons to other groups indicated that all were consistently measuring the same "wrong" value for the period even though the theoretical predictions were similar across the classroom. This led some groups to bring out microcomputer-based lab equipment to make more accurate measurements, which merely confirmed their earlier data. Other students tried setting up computer simulations that verified their theoretical predictions but didn't fit the real world data. There was definitely a problem.

The instructor, through Socratic dialog, was able to bring about a third of the groups to the realization that the mass of the spring was influencing the situation. (The instructor made a conscious effort not to simply reveal the answer.) The rest of the groups overheard what was going on and the entire class went about trying to find a way to correct for the fact that the mass of the spring itself was greater than the mass hanging from it. Eventually they discovered that they could model the situation as a series of masses with stiffer springs between them. Doing so not only resulted in a simulation that correctly matched the measured period, but it also displayed the amplitude variations (from internal vibrations) that the students originally attributed to spurious noise in the MBL data. This activity, which the students believed would only take a few minutes, ended up lasting an hour and a half. (Never knowing what to expect in class proved to be an excellent motivator.) The unsolicited e-mail comment of one of the students is noteworthy:

"I just want to say that the lab you had for us yesterday [sic] was very interesting. I was pretty frustrated with it at first but in the end I did learn a lot more about SHM. Just wanted to tell you. Have a great day.",

As the year progressed, it became increasingly apparent that the class members were challenging each other and their teachers as they constructed their own understanding. The strong group ties that were cultivated throughout the courses let students quietly "check with their neighbor' before raising a question or pointing out an area of difficulty. This support for each other was seen in many situations and will be discussed in more detail later.

Most of the data presented in this paper was collected during the Spring 97 semester when the 5th edition of Halliday, Resnick, and Walker ${ }^{24}$ was used as the physics text. In the previous year Reif's text ${ }^{25}$ was used.

\section{EVALUATION AND ASSESSMENT}

\section{A. IMPEC and control populations}

In the summers of 1995 and 1996, incoming freshman engineering students received letters inviting them to a special meeting held during orientation before the beginning of the fall semester. Those attending were introduced to the IMPEC (Integrated Math, Physics, Engineering, and Chemistry Curriculum) faculty and the types of instruction that would be presented in the upcoming two semesters, and were invited to enroll in IMPEC. Each year we had about twice as many student volunteers as openings in the experimental classes. This allowed us to admit approximately half those volunteering for the program and track the others in their regular courses, thus adjusting for bias that might be present because of the voluntary nature of student participation in the project. The IMPEC class members were selected at random from the group of volunteers, except for the constraint that we wanted the experimental courses to have the same gender and racial demographics as the entire engineering freshman student body. We will present comparisons of academic performance and attitudes for two different academic years. We did not track nonselected volunteers during the second year of the study. The Spring 97 IMPEC physics instructor (RJB) also presented instruction in a lecture hall setting to a group of 78 physics students in the fall of 1997 . They were examined as a control group for specific concepts in physics.

\section{B. Qualitative procedures}

The regular collection and subsequent analysis of the class' electronic Listserv mail was just one of a wide variety of approaches taken to help us understand what was going on in the classroom and to provide insight into what the students were thinking. Each technique yielded a different view of the scene. Comparing and contrasting qualitative and quantitative data built up a more complete picture.

Throughout the Spring 1996 semester one of the researchers (RJB) attended the physics class and recorded field notes from observations. In the fall of 1996 he observed all the classes and collected notes and videotape. The bulk of the $200+$ hours of notes were straightforward recordings of as many of the teacher-student and student-student activities as possible. Videotapes were made for comparison to the handwritten notes, to ensure valid and reasonably complete data collection. Most of the field observations comprised whole-class observations (during teacher-directed instruction) along with close, but noninterfering, recording of group interactions. In addition, several days were spent making timed observations where specific activities were noted at regular intervals - a "sweep" of the classroom was completed every $2 \mathrm{~min}$.

Notes were also recorded during or immediately after nonstructured and structured interviews with individual students and groups. These were supplemented with a variety of surveys that were administered throughout the year.

To analyze this large body of qualitative data, an adaptation of Strauss and Corbin's ${ }^{26}$ Grounded Theory methodology was employed, progressing from open to axial coding. A rainbow of highlighters was used to perform multiple catego- 
rization of the notes. A legend relating each color to a category was slowly built up as the researchers made their way through the information and created new classifications (open coding) as they read. Each additional pass through the data brought slight modifications to previous categories or new combinations or splitting of categories (axial coding) until a final, fairly stable classification scheme was induced from the tall stack of field notes. Different researchers compared their categories to improve the validity of the effort. Strauss and Corbin's approach of selective coding led to the recognition of the critical importance of socialization in the classroom.

We also kept copies of student work. These portfolios of exams, diagnostic tests, labs, and other materials were compared to the classroom observations and interviews. Questionnaires gave students the opportunity to directly report their impressions of the learning environment. We specifically looked for places where the different data streams confirmed and disputed other analyses. This triangulation adds considerably to the validity of the qualitative research and strengthens our commitment to the conclusions we have reached.

\section{Quantitative assessment}

The sizable battery of quantitative assessments included the Force Concept Inventory, ${ }^{27}$ and the Test of Understanding Graphs in Kinematics. ${ }^{28}$ In addition to these two concept assessments, we attempted to evaluate problem-solving skills by replicating the calculation-oriented problems from the traditional class exams. (These tests are prepared by one of the Physics Department's faculty members who has had this task for more than a decade. They are reviewed by other faculty for completeness and as an error check.) Both experimental and control group students took a common final exam that was prepared in the same manner.

\section{RESULTS}

\section{A. Qualitative data}

We will first consider the findings of the qualitative research. We developed the following broad categories from the iterative analysis of field notes: socialization, metacognition \& team skills, esteem building (from faculty), task orientation, and critical thinking. Each area was followed through the notes and general trends for each were noted. We also tried to quantify data where appropriate. For example, $2 / 3$ of the e-mail from students originated from approximately $1 / 3$ of the students, but it was fairly evenly distributed among these main contributors. The remaining students averaged less than one message per week. Note that we have no records for direct student-to-student e-mail. They appeared to utilize the class Listserv almost exclusively for communication with each other.

We categorized 439 e-mail messages from the 96-97 class (Fig. 1) and discovered, not unexpectedly, that socialization-basically nothing more than friendly conversation-was the main student use of the network. (These students were still using the Listserv to communicate with each other more than a year after their direct involvement in IMPEC was over.) Messages that directly related to course material were relatively infrequent. Faculty messages dealt with course content more frequently, but socialization—and particularly noteworthy,

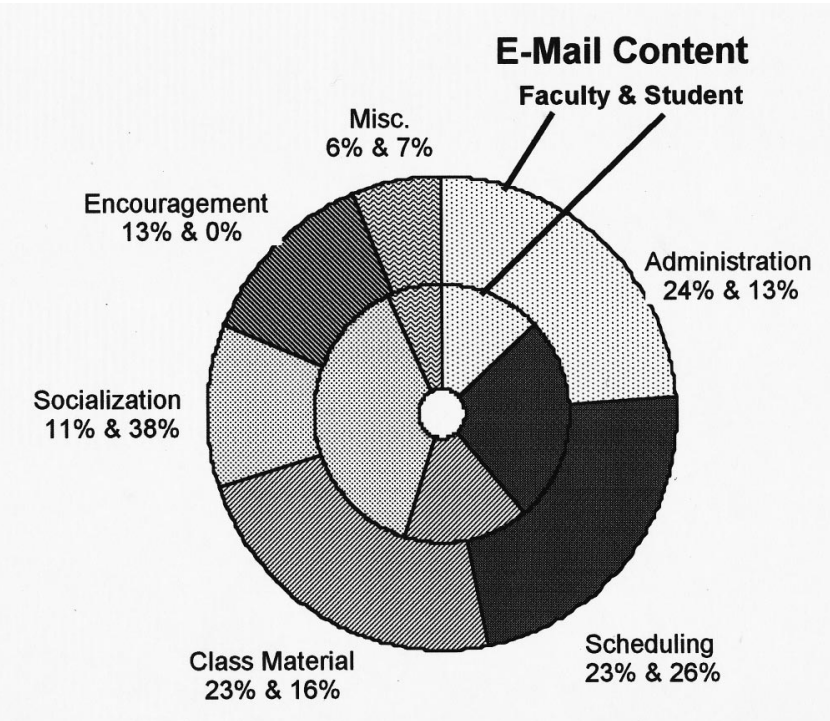

Fig. 1.

encouragement-made up a substantial fraction of their notes to the class. Course administration was a common topic of the instructors' messages. (The only papers distributed to students in the physics course were the exams.)

Several interesting findings emerged from our review of the field note and videotape data. First of all, it became quite apparent that the same students, in the same room, working in the same groups, responded differently to different teachers. Although all students appeared to respect all the faculty they were dealing with, their interactions depended greatly on the personalities involved. This in itself is not surprising, but it was interesting to see it so clearly in this situation where everything else was held fairly constant. What we found that was unusual is that it was possible, through a directed effort, to change the nature of these interactions. In one case it was noted that the level of questioning presented by a faculty member was rather shallow, of a sort we called "fill-in-the-blank" sentences. For example, during a presentation, the following was recorded:

Instructor: "The slope of this line is...one, right?" Contemporaneous field notes:"Short wait time, short response time. Student responses very superficial."'

Analysis notes: "Superficial questions keep students in class, but perhaps not deep into material."

Many questions were followed by a very short (typically less than a second) waiting interval. The instructor then filled in the blank for the students. Students became rather passive in these situations even though for other aspects of the same class and for other faculty they were quite aggressive in their responses and challenging with their own questions. When they could be persuaded to react to the fill-in-the-blank questions, their answers were typically very brief. After a discussion of the problem among the project faculty, the instructor began paying particular attention to the types of questions he asked and their mode of presentation. It took several days for the students to begin reacting to these modifications. But soon they began to take more active roles in this portion of the class and were putting considerable effort into answering the more demanding questions posed to them by their instructor, especially when an adequate wait time was incorporated into the instruction. Of course, this has been born out in 
Table I. Comparison of overall success rates and passing rates for females and minorities. (Success is defined as grades of $\mathrm{C}$ or better in two math courses, chemistry, physics, and engineering.) Rates are given as percentages.

\begin{tabular}{|c|c|c|c|c|c|c|c|c|}
\hline & \multicolumn{4}{|c|}{ 1995-96 Academic year } & \multicolumn{4}{|c|}{ 1996-97 Academic year } \\
\hline & $N$ & $\begin{array}{l}\text { Success } \\
\text { rate }\end{array}$ & $\begin{array}{c}\text { Female } \\
\text { pass rate }\end{array}$ & $\begin{array}{l}\text { Minority } \\
\text { pass rate }\end{array}$ & $N$ & $\begin{array}{l}\text { Success } \\
\text { rate }\end{array}$ & $\begin{array}{c}\text { Female } \\
\text { pass rate }\end{array}$ & $\begin{array}{l}\text { Minority } \\
\text { pass rate }\end{array}$ \\
\hline IMPEC & 35 & $69 \%$ & $60 \%$ & $100 \%$ & 36 & $78 \%$ & $67 \%$ & $100 \%$ \\
\hline Nonselected volunteers & 31 & $52 \%$ & $\cdots$ & $\cdots$ & $\cdots$ & $\cdots$ & $\cdots$ & $\cdots$ \\
\hline Traditional & 736 & $52 \%$ & $45 \%$ & $20 \%$ & 552 & $50 \%$ & $43 \%$ & $20 \%$ \\
\hline
\end{tabular}

the classic study by Rowe, ${ }^{29}$ but the ability to change student responses as a result of specifically modifying the type of questions asked is a useful finding. We believe this indicates that it is possible to make directed efforts to improve teaching and the results can be immediate and tangible. In this case, it also illustrates the value of peer (as in instructorinstructor) learning.

We experimented with several different classroom layouts, requesting feedback from both faculty and students to supplement the field notes. An interaction analysis led to the nonsurprising conclusion that long, rectangular tables were not particularly well suited for group work. We had much more success with round tables. Students adjusted seating to fit their needs at the time and both within-group and between-group communications were much more commonly observed than when these same students were at rectangular tables. The circular tables also promoted easy movement of the instructor from group to group while providing convenient access to individuals. Table diameter did not appear to have a substantial impact on classroom interactions, although students preferred the extra space provided by a larger table. We also placed different numbers of students at computers to ascertain how to best utilize the technology. We did not reach any conclusions in this area other than the ratio of two computers per three students was not effective. (Often one of the computers would go unused or else the one student of a trio who did not have a computer would go back and forth, looking over the shoulders of the two students who did.) We did note that large monitors on the tables interfered with inter-group discussions.

Overall, the qualitative data indicated a successful implementation of the learning environment. This is perhaps most evident from the results of the standard (used by all service courses in the NCSU Physics Department) end-of-semester course evaluation. Students were asked to indicate their general satisfaction with the course, on a Likert scale with 1 being "Not at all satisfied" and 5 reporting "Very satisfied." Of the last two classes queried, all but one student selected 5. The lone holdout chose 4 .

\section{B. Quantitative results}

While the qualitative data of this study shed light primarily on the day to day interactions in the classroom, the quantitative information we gathered examined academic performance for the most part. Most of the results are shown in Table I.

During the first year of the study we compared the success rate (the percentage of students with grades of $\mathrm{C}$ or better in science, math, and engineering courses) of IMPEC students with the other volunteers who had not been selected to participate. Comparisons were also made with the rest of the demographically matched students in the traditional course sequence. The IMPEC students were much more successful than either of the control groups. Although this indicates that there was probably not a bias favoring the IMPEC students because they were volunteers, it is possible that people who had shown an interest in a highly interactive learning situation were disappointed when they were not selected and this affected their performance in the traditional classes. Note, however, that the success rate of the nonselected volunteers in 1995-1996 is approximately the same as the success rate for the traditional students.

Our concern with volunteer bias was an outgrowth of our desire to conduct a valid study. We were actually much more interested in examining the effect of the experimental curriculum on students who are typically underrepresented in science, math, and engineering fields. Table I shows that in 1995-96, the core course passing rate for all the IMPEC students was significantly higher (Wilcoxon test, $p<0.1$ ) than that for the control group of volunteers and for the freshman engineering class as a whole. In 1996-97, the performance differences $(p<0.01)$ between IMPEC and nonIMPEC students were even greater. But we were especially pleased to see that for both years, the passing rates for IMPEC women were much higher than the rates for their non-IMPEC counterparts. And it is noteworthy that all the African-American students in IMPEC passed each year.

Beyond the rather coarse measures of "passing", or "success," evidence from a variety of assessments suggests that the quality of learning was high relative to that for students in the traditional first year course sequence. Compared to students in the control group and to all the students in the regular freshman orientation course, the IMPEC students finished with significantly higher levels of confidence in their abilities in science and mathematics, writing, speaking, and computer skills. Most of the final engineering project reports and presentations were surprisingly good (with some outside faculty observers comparing them to senior papers), and IMPEC helped confirm the decision to major in engineering for a large percentage of the students who successfully completed the curriculum. A number of measures of student satisfaction and confidence levels in various skills were utilized. The results were disturbing in that students in the regular courses (both those who had volunteered for IMPEC but were not selected and the rest of the engineering freshman) had lowered self-confidence levels. This is seen in Figs. 2 and 3. Students who had indicated interest in the IMPEC curriculum but were not selected to participate appeared to be the most adversely affected. More details of these attitudinal surveys can be found in Felder et al. ${ }^{30,31}$

Although positive attitudes are valued, engineers are in the problem-solving business. Engineering faculty rate problem 


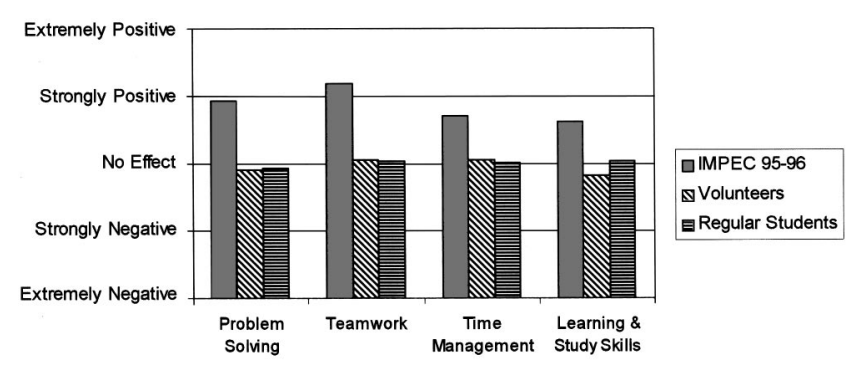

Fig. 2.

solving as a vital skill that their students need to acquire. We assessed this ability by utilizing the exams developed for the traditional students by the Physics Department. Figure 4 illustrates that the IMPEC students did better on the shared mid-semester exam questions, averaging $80 \%$ as compared to $68 \%$ for the traditional students, even though both populations were carefully matched in scholastic achievement and demographics. The IMPEC students' grades on the common final exam were nearly half a letter grade higher than their traditionally taught peers.

Knowing that it is possible for students to perform fairly well on typical problem-oriented exams while still having substantial gaps in their understanding, we conducted several conceptual evaluations as well. Kinematics graph interpretation scores (on the TUG-K) averaged $89 \pm 2 \%$ for IMPEC students while their peers at other institutions made only $48 \pm 2 \%$. (The uncertainties are percentages derived from the standard error of measurement, $\sigma / \sqrt{N}$.) This astonishing result caused us to worry about instructional bias, especially since the instructor had previously developed the testing instrument. ${ }^{28} \mathrm{~A}$ visiting faculty member (not part of the research team) was acting as an outside observer during the physics classes. Before revealing the results of the TUG-K administration, we asked him to review his notes and the instrument and comment on whether he thought the instruc-
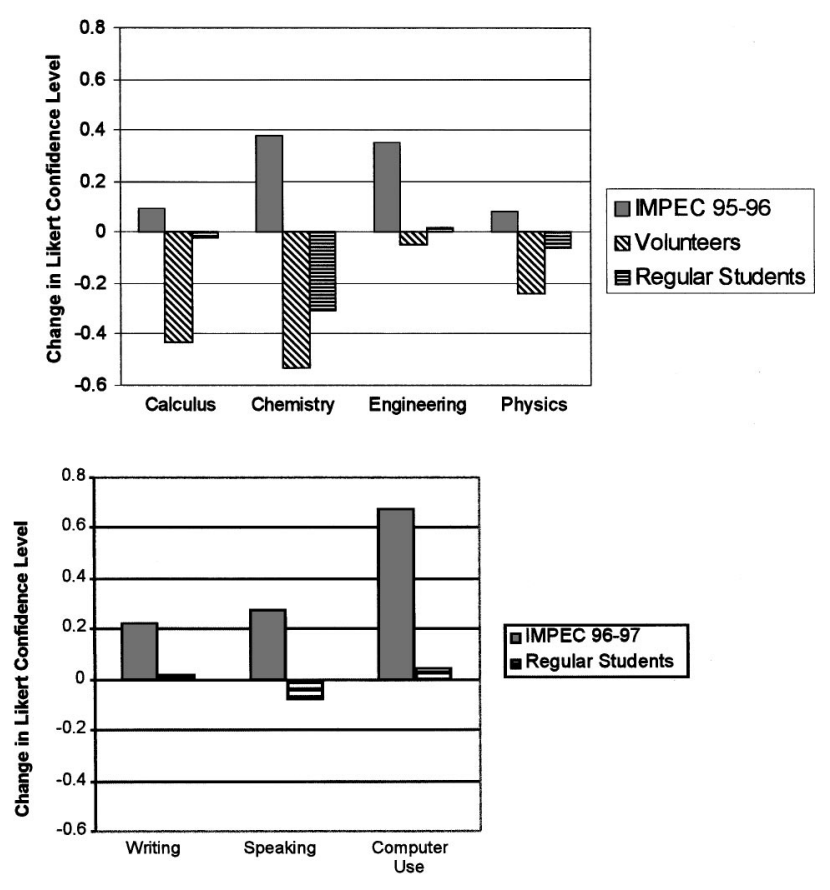

Fig. 3.

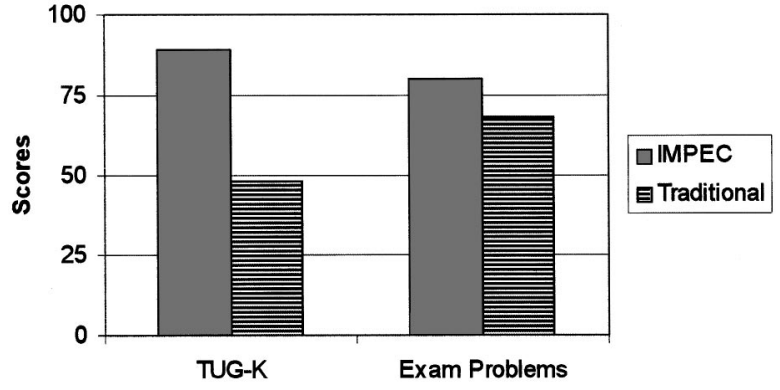

Fig. 4.

tor "taught to the test." His response was that although the course dealt with the same content (as it should), the individual test items were not part of the instruction. In his opinion, the test results were valid.

Table II and Fig. 5 show that the 1995-96 IMPEC students performed at a much higher level on the Force Concept Inventory (FCI) than did a national sample of traditionally taught students. The 1996-97 group even did better than students in many other innovative "interactive engagement" courses. This is not believed to be due to a teacher effect since the same instructor taught a control group (via traditional instruction in a lecture hall) where the FCI gain was actually slightly lower than the national norm for traditional instruction, much to his dismay.

As a follow-up, we tracked the 1995-96 students who took the electricity and magnetism course (which was traditionally taught) in the following semester. There was no significant difference between them and their peers on exam performance, $t(19,0.05)=0.50$. We did not really know what to expect. On the one hand, one could hope that the critical thinking and problem-solving skills that had been part of the previous semester's instruction would help students in all their subsequent courses, even if those courses were traditionally taught. Conversely, we were concerned that after exposure to the highly engaging nature of the experimental instruction, the students might react negatively to lecture-based teaching and end up doing poorly. In the end, it did not appear to make any difference on standard exam performance, although this may be due to the nature of the tests. It would have been interesting to test both groups of students on more complex, content-rich problems to see if the post-IMPEC group could apply their training on such problems to new situations. Although the students did continue to socialize, we have no data as to whether they used the group-related skills they learned as participants in IMPEC.

\section{DISCUSSION}

\section{A. Socialization is critical}

We believe the most important finding from our analysis of the qualitative data is the central role that socialization played in the success of the students. For example, during an unstructured (where the student led the direction of the discussion) interview, a student was recalling the previous semester and said, "....because we [emphasis added] made a B in engineering..." unconsciously referring to her group members. We also saw evidence of long-term commitments being made among the students, including plans to room together in subsequent semesters and even to "gang- 
Table II. Comparison of the groups to a national sample on $\langle g\rangle$, Hake's normalized gain factor (Ref. 9) (the fraction of the maximum possible gain in score from pretest to post-test) for the Force Concept Inventory. Significance of comparisons are based on unequal variances one-tailed $t$-tests at the $\alpha=0.05$ confidence level. The Spring 97 IMPEC group $\langle g\rangle$ was also significantly higher (equal variances $t=2.86, d f=4491$ ) than the mean for the interactively taught students in Hake's national sample. Note that the same instructor taught the IMPEC Spring 97 and the local traditional course as a control in Fall 97.

\begin{tabular}{lccccc}
\hline \hline & Class & $N$ & $\langle g\rangle$ & $\begin{array}{c}\text { Statistical } \\
\text { results }\end{array}$ & $\begin{array}{c}\text { Significant difference } \\
\text { compared to national } \\
\text { sample (traditional) }\end{array}$ \\
\hline $\begin{array}{l}\text { National } \\
\text { sample (Ref. 9) }\end{array}$ & Traditional & 2084 & $0.23 \pm 0.04$ & & \\
& Interactive & 4458 & $0.48 \pm 0.14$ & & Higher \\
$\begin{array}{l}\text { IMPEC } \\
\text { students }\end{array}$ & Spring 96 & 30 & $0.42 \pm 0.06$ & $\begin{array}{l}t(d f=29) \\
=18.9 \\
t(d f=34) \\
=36.5\end{array}$ & Higher \\
& Spring 97 & 35 & $0.55 \pm 0.05$ & $\begin{array}{l}t(d f=76) \\
=3.96\end{array}$ & $\begin{array}{l}\text { Lower } \\
\text { Lower }\end{array}$ \\
\hline $\begin{array}{l}\text { Control } \\
\text { group }\end{array}$ & Fall 97 & 77 & $0.21 \pm 0.04$ & &
\end{tabular}

register" for non-IMPEC classes so that they could continue their collaborations. This phenomenon is seen in the following two excerpts from the class' Listserv messages:

"There is a lab on thursday from 12:50-3:40 that only has 16 people in it. If we all tried to get into that one we would be over half the lab!",

“'guys, i'm compiling a list of summer phone numbers so we don't lose touch...."

The electronic mail system also revealed how the class members functioned as a support group. These notes to the entire class are from two different students:

"I made some hasty decisions at the beginning [sic] of the semester (fraternity involvement) and in addition to that I wrecked my car, my great uncle died, I ran out of money, and my mother was rushed to the emergency room one Friday night. Without your unconditional support and kindness, there is no way that I would have made it through this semester."

"it isn't often that you get a chance to realize how many friends you truly have...so, this note goes out to all of the students and professors that are in impec...you guys were $110 \%$ supportive through my recent ordeal and that really means a lot to me...."

The last major area of social interaction that was carefully scrutinized was that of gender and race issues. We were very pleased to see that these barriers were nonexistent, as far as we could tell. Based on reviews of videotapes and field

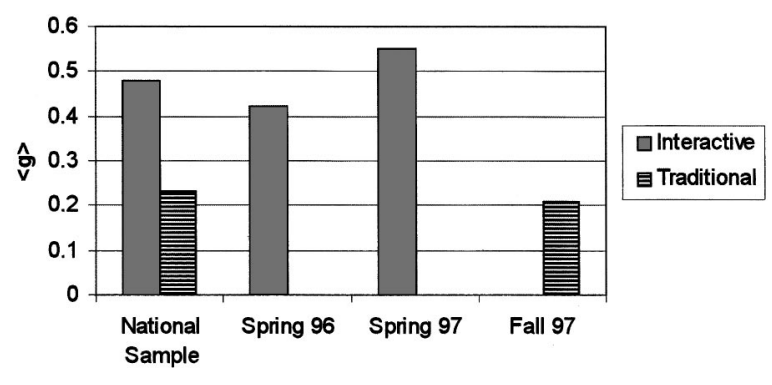

Fig. 5. notes, minorities and females appeared to be just as involved in class discussions and group work as the rest of the students. This is consistent with data from e-mail records that indicates African-American students, making up $14 \%$ of the class, sent $16 \%$ of the messages. Females, $17 \%$ of the IMPEC students, sent $22 \%$ of the e-mail. An incident from the field notes is particularly revealing of the lowering of racial barriers. Students were preparing to give end-ofsemester presentations and an instructor complimented student $\mathrm{K}$ about his clothing.

Instructor: "That's a pretty flashy tie!"

$K$ [a white student]: "Yeah! [smiling, then points to $J$, an African-American student] It's $J$ 's. In fact, this whole outfit [motioning to his suit coat and pants] is his!"

\section{B. Technology and activities were important in establishing the learning environment}

Because of the central role of technology in this curriculum, we paid close attention to how students utilized it. Although there were many examples of students being drawn off task by having access to electronic mail and the web during class, these situations were readily corrected by a request to turn the monitors off. What is more important to note is how the assignment of a computer-related task brought everyone back to the topic at hand. Students who had not been actively engaged in the discussion quickly became involved when they had to "tell the technology" to do something for them. We see this as a variant of the peer instruction that often goes on during group work. Because the students had to focus their attention on what they wanted the software or hardware to do, they were much more easily kept on task. This pattern was seen repeatedly with different teachers throughout both years. Of course, the use of technology as a means for students to gather data and analyze it meant that the instructor did not have to be "up front and talking" for most of the class time. He was free to move about the classroom, making inquiries and offering guidance where and when it was needed. The focus was kept on the phenomenon being studied rather than on an authority talking about the phenomenon. 


\section{CONCLUSIONS}

The type of instruction used in the experimental courses-a highly collaborative, technology-rich, activitybased learning environment-had a substantial positive effect on the students' conceptual understanding, problemsolving skills, attitudes toward the courses, and confidence levels. We believe that the socialization promoted by IMPEC's cooperative learning environment was the most critical factor in these gains, although there was probably a synergistic effect from the active learning and technology orientation of the instruction.

Much additional work remains. We would like to study the relative importance of the different teaching methods used in these classes. Students seemed to respond most positively when many instructors used many different techniques in a fairly short time period. The changing roles and relationships of instructors and students would also be an interesting subject of study. Moreover, since attitudes seemed to be so strongly impacted, we should take advantage of newer assessment instruments like the VASS $^{32}$ and MPEX ${ }^{33}$ tests to provide additional insight.

Because of the great success of this experiment in terms of both performance and attitudes, we feel it is absolutely critical to find a way to maximize the "exportability" of this approach to instruction. We have begun a related project called SCALE-UP (Student Centered Activities for Large Enrollment University Physics) where we are continuing these efforts. The task is to maintain the engaging learning environment in classrooms of 100 students. Teacher guides and classroom materials from the project will be made available to schools interested in reforming their introductory physics instruction. Visit http://www.NCSU.edu/PER for more information.

\section{ACKNOWLEDGMENTS}

The authors would like to express our appreciation to the National Science Foundation, which supported this study through SUCCEED Coalition funding. Thanks are also extended to Dr. Jeffery Saul, who provided useful feedback during the writing of this article.

\section{APPENDIX}

\section{Engineering orientation courses}

During the fall semester, students were exposed to the different engineering disciplines and introduced to the campus computer network. A graduate of the NCSU engineering program visited the class and spoke about life in the "real world," and a field trip to a chemical plant included discussions with several on-site engineers. During both fall and spring semesters, strong emphasis was placed on how different types of engineering would be utilized in complex problems that integrated content areas. For example, in the Fall of 1996, student teams worked on a lengthy project where they designed a shower system for a recreational vehicle incorporating a propane burner and heat exchanger, and prepared a thorough written report and oral presentation. The following semester had them studying the engineering of racing cars and finding the applications of math and physics in the design of high performance automobiles. The engineering courses were where most of the integration of topical material was emphasized and where students received explicit instruction in communication and teamwork, project man- agement, technical written and oral presentation, and principles of metacognition. Landis's Studying Engineering ${ }^{34}$ was used as a text.

\section{Math courses}

Here the students used the Hughes-Hallett Calculus text $\mathrm{t}^{35}$ that forms the basis of the Harvard calculus reform effort. MAPLE, a symbolic and numerical mathematics program, was used heavily as an instructional tool and for completing assignments. Students become quite good at using the software and would spontaneously utilize it in their other courses for solving problems. There were many "hands-on" activities where students explored the behavior of functions or built intuitive understandings of procedures like differentiation and integration.

\section{Chemistry course}

In the fall, students used the Chang Chemistry text ${ }^{36}$ and a locally produced study packet. Exploring Chemistry and Introduction to General Chemistry, distributed by Falcon Software, were also used frequently. A separate wet chemistry laboratory was the only component of the entire IMPEC curriculum that met in a separate room.

${ }^{1}$ A. W. Astin, "Engineering Outcomes," ASEE Prism 27-30 (Sept. 1993). ${ }^{2}$ R. W. Heckel, "Engineering Freshman Enrollments: Critical and Noncritical Factors," J. Engr. Educ. 85, 15-21 (1996).

${ }^{3}$ L. C. McDermott, "Millikan Lecture 1990: What we teach and what is learned-Closing the gap," Am. J. Phys. 59, 301-315 (1991).

${ }^{4} \mathrm{D}$. Hestenes, "Toward a Modeling Theory of Physics Instruction," Am. J. Phys. 55, 440-454 (1987).

${ }^{5}$ J. H. Larkin, "Expert and novice performance in solving physics problems," Science 208, 1335-1342 (1980).

${ }^{6}$ L. C. McDermott, Physics by Inquiry (Wiley, New York, 1997).

${ }^{7}$ P. Laws, Workshop Physics Activity Guide (Wiley, New York, 1997).

${ }^{8}$ J. M. Wilson, “The CUPLE Physics Studio," Phys. Teach. 32, 518-523 (1994).

${ }^{9}$ R. R. Hake, "Interactive-engagement vs traditional methods: A sixthousand-student survey of mechanics test data for introductory physics courses," Am. J. Phys. 66, 64-74 (1998).

${ }^{10} \mathrm{D}$. Johnson, R. Johnson, and K. Smith, “Cooperative Learning: Increasing College Faculty Instructional Productivity," ASHE-ERIC Higher Education Report No. 4 (The George Washington University, School of Education and Human Development, Washington, DC, 1991).

${ }^{11}$ R. M. Felder and R. Brent, "'Cooperative Learning in Technical Courses: Procedures, Pitfalls, and Payoffs," ERIC Document Reproduction Service, ED 377038 (1994).

${ }^{12}$ B. Panitz, "The Integrated Curriculum," ASEE Prism 24-29 (Sept. 1997).

${ }^{13}$ T. Foster and P. Heller, "Problem solving labs at the University of Minnesota. 1. Context-rich problems,'” AAPT Announcer 26 (2), 79 (1996); P. Heller, R. Keith, and S. Anderson, "Teaching problem solving through cooperative grouping. 1. Group versus individual problem solving," Am. J. Phys. 60, 627-636 (1992).

${ }^{14} \mathrm{R}$. Chabay and B. Sherwood, "Where is the physics in homework problems?" AAPT Announcer 26 (2), 104 (1996).

${ }^{15} \mathrm{H}$. Brasell, "The Effect of Real-time Laboratory Graphing on Learning Graphic Representations of Distance and Velocity,' J. Res. Sci. Teach. 24, 385-395 (1987).

${ }^{16} \mathrm{R}$. Beichner, "Impact of video motion analysis on kinematics graph interpretation skills," Am. J. Phys. 64, 1272-1278 (1996).

${ }^{17}$ E. F. Redish, J. M. Saul, and R. N. Steinberg, "On the effectiveness of active-engagement microcomputer-based laboratories," Am. J. Phys. 65, 45-54 (1997).

${ }^{18} \mathrm{~A}$. Arons, A Guide to Introductory Physics Teaching (Wiley, New York, 1990).

${ }^{19}$ Excel Inc., Learning Type Measure (Excel Inc., Barrington, IL, 1987).

${ }^{20}$ See Ref. 7. See also P. Laws, "Calculus-based physics without lectures," Phys. Today 44, 24-31 (1991). 
${ }^{21}$ E. Mazur, Peer Instruction: A User's Manual (Prentice-Hall, Upper Saddle River, NJ, 1997).

${ }^{22}$ A. Van Heuvelen, Overview: Case Study Physics; Study Guide I (The Ohio State U.P., Columbus, OH, 1995).

${ }^{23}$ R. R. Hake, "Socratic pedagogy in the introductory physics laboratory," Phys. Teach. 30, 546-552 (1992).

${ }^{24}$ D. Halliday, R. Resnick, and J. Walker, Fundamentals of Physics (Wiley, New York, 1997), 5th ed., Vol. 1.

${ }^{25}$ F. Reif, Understanding Basic Mechanics (Wiley, New York, 1995).

${ }^{26}$ A. Strauss and J. Corbin, Basics of Qualitative Research: Grounded Theory Procedures and Techniques (SAGE, Newbury Park, CA, 1990).

${ }^{27}$ D. Hestenes, M. Wells, and Swackhamer, "Force concept inventory,', Phys. Teach. 30, 141-158 (1992).

${ }^{28} \mathrm{R}$. Beichner, "Testing student interpretation of kinematics graphs," Am. J. Phys. 62, 750-762 (1994).

${ }^{29}$ M. Rowe, "Wait-time and rewards as instructional variables, their influence on language, logic and fate control: Part one-Wait time,' J. Res. Sci. Teach. 11, 263-279 (1974).

${ }^{30}$ R. M. Felder, L. E. Bernold, E. E. Burniston, P. R. Dail, H. Fuller, and J.
E. Gastineau, "IMPEC: Integrated Mathematics, Physics, Engineering, and Chemistry Curriculum," 1996 Report to the National Science Foundation, N.C. State University, November 1996.

${ }^{31}$ R. M. Felder, R. Beichner, L. E. Bernold, E. E. Burniston, P. R. Dail, and H. Fuller, 'IMPEC: Integrated Mathematics, Physics, Engineering, and Chemistry Curriculum,' 1997 Report to the National Science Foundation, N.C. State University (unpublished).

${ }^{32}$ I. Halloun, "Views about science and physics achievement: The VASS story, " in The Changing Role of Physics Departments in Modern Universities: Proceedings of the International Conference on Undergraduate Physics Education, College Park, MD, 31 July-3 August 1996, edited by E. F. Redish and J. S. Rigden (AIP Press, Woodbury, NY, 1997), pp. 605-613.

${ }^{33}$ E. F. Redish, J. M. Saul, and R. N. Steinberg, "Student expectations in introductory physics,', Am. J. Phys. 66, 212-224 (1998).

${ }^{34}$ R. Landis, Studying Engineering (Discovery, Burbank, CA, 1995).

${ }^{35}$ D. Hughes-Hallett et al., Calculus (Wiley, New York, 1994).

${ }^{36}$ R. Chang, Chemistry (McGraw-Hill, New York, 1994), 5th ed.

Winning coaches, for example, recognize the different learning styles of their players. Former Raiders coach John Maden says that for some players you simply tell them the play and they know it; others must be shown diagrams before they can form their own mental image of what to do; and still others won't really grasp the play until they physically run through it so that they can feel the play as well as see and hear it. The same is true for the "coaches" of military recruits and corporate training programs.

Quoted in “'The Now Habit”' by Neil A. Fiore, page 180, Jeremy P. Tarcher, Inc., Los Angeles, CA, 1989 (Distributed by St. Martin's Press, NY). 